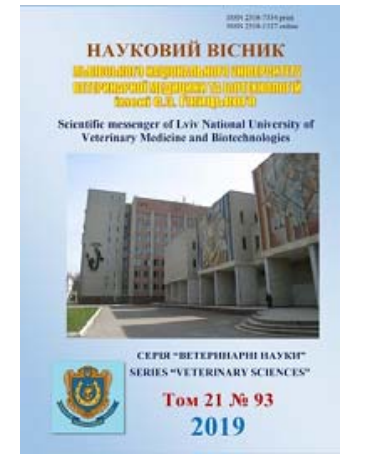

Науковий вісник Дьвівського національного університету ветеринарної медицини та біотехнологій імені С.З. Гжицького. Серія: Ветеринарні науки

Scientific Messenger of Lviv National University of Veterinary Medicine and Biotechnologies. Series: Veterinary sciences

UDC 599. 74: 591. 493

\title{
The structural features of the sculls of animals of a series of Carnivore
}

\author{
T.F. Kot, I.M. Lutsiuk, O.V. Synytskyi \\ Zhytomyr National Agroecological University, Zhytomyr, Ukraine
}

Article info

Received 23.01.2019

Received in revised form 06.03.2019

Accepted 07.03.2019

Zhytomyr National Agroecological University, Stary Boulevard, 7 ,

Zhytomyr, 10008, Ukraine.

Tel.: +38-098-211-48-33

E-mail: tkotvet@ukr.net
Kot, T.F., Lutsiuk, I.M., \& Synytskyi, O.V. (2019). The structural features of the sculls of animals of a series of Carnivore. Scientific Messenger of Lviv National University of Veterinary Medicine and Biotechnologies. Series: Veterinary sciences, 21(93), 65-69. doi: 10.32718/nvlvet9312

Predators is medium-sized and large mammal leading a terrestrial way of life. They are mostly carnivorous animals, the nature of nutrition of which indicate certain devices are reflected in the structure of the scull. The aim of the work is to conduct a comparative anatomical study of the structure of the scull and to determine the craniometric indicators in animals of families Feline (Domestic cat), Canine (Domestic dog, Wolf, Fox ordinary) and Mustelidae (stone marten, forest polecat, badger ordinary) a squad of Carnivore. Comparative anatomical, craniological and statistical methods of research were used. It was found that the scull of test animals is of a General anatomical structure (wide temporal fossa, a deep masseteric fossa, well-defined nuchal and external sagittal crests, the presence of angular process on mandible, relatively large tympanic bullas, underdeveloped lacrimal bone) and species differences (topography of split of the external sagittal crest, shape of mandibular angular process, the presence of intratympanical part of the temporal bone). Absolute craniometrical indices of badger more of indicators of marten, since they directly depend on the weight and body size of these animals. There are most vary the overall length of the scull (1.69 times; $P<0.001)$, length of bony palate (1.82 times; $P<0.001)$, length of the external sagittal crest (3.67 times; $P<0.001)$, width of bony palate at the level of the first premolar and the last molar $(2.33$ times; $P<0.001)$, width of choans on the level of hook-shaped processes of pterygoid bone (1.75 times; $P<$ $0.01)$, width of choans at the level of the caudal edge of the Palatine bone (2 times; $P<0.05)$, the total height of the scull $(2.36$ times; $P<0.001)$. Most of the relative craniometric indicators of the badger scull, compared with such in martens, are almost the same, due to the close specificity of nutrition and environmental characteristics in natural biocenosis. Due to the well-developed external sagittal crest, the height of the brain relative to the total height of the scull in badger $(61.02 \pm 4.73 \%)$ is 1.51 times less $(P<0.001)$ than in marten $(92 \pm 6.12 \%)$. The relative length of the external sagittal crest to the total length of the badger scull is 2.17 times longer $(P<0.001)(53.1 \pm 3.09$ versus $24.42 \pm 1.41 \%)$, compared with marten, due to the more powerful development of masticatory muscles, temporal in particular.

Key words: head skeleton, carnivores, morphology, craniometry.

\section{Особливості будови черепа тварин ряду Хижі}

\author{
Т.Ф. Кот, I.М. Луцюк, О.В. Синицький
}

Житомирський національний агроекологічний університет, м. Житомир, Украӥна

\footnotetext{
Хижі - середні та великі ссавиі, що ведуть наземний спосіб життя. Переважно м'ясоїдні тварини, про характер живлення яких свідчать певні пристосування, відображені у будові черепа. Мета роботи - провести порівняльно-анатомічні дослідження будови черепа і визначити краніометричні показники у тварин родин Котячі (кіт свійський), Собачі (собака свійська, вовк, лисиия звичайна) і Куницеві (куниия кам'яна, тхір лісовий, борсук звичайний) ряду Хижі. Використали порівняльно-анатомічні, краніологічні та статистичні методи досліджень. Встановили, що череп досліджених тварин має спільні анатомічні особливості будови (широка вискова ямка, глибока жувальна ямка, добре виражені карковий $і$ зовнішній сагітальний гребені, наявність кутового відростка на нижній щелепі, відносно великі барабанні міхури, слабо розвинена слізна кістка) і видові відмінності (топографія роздвоєння зовнішнього сагітального гребеня, форма нижньощелепного кутового відростка, наявність внутрішньобарабанної
} 
частини вискової кістки). Абсолютні краніометричні показники борсука більші за такі показники куниці, оскільки прямо залежать від маси та розмірів тіла ичих тварин. Найбільш різняться показники загальної довжини черепа (в 1,69 раза; $P$ < 0,001), довжини кісткового піднебіння (в 1,82 разу; $P<0,001)$, довжини зовнішнього сагітального гребеня (в 3,67 раза; $P<0,001)$, иирини кісткового піднебіння на рівні першого премоляра і останнього моляра (в 2,33 разу; $P<0,001)$, ширини хоан на рівні гачкоподібних відростків крилоподібної кістки (в 1,75 раза; $P<0,01)$, ширини хоан на рівні каудального краю піднебінної кістки (в 2 рази; $P<0,05)$, загальної висоти черепа (в 2,36 разу; $P<0,001)$. Більшість відносних краніометричних показників черепа борсука, порівняно $з$ такими в куниці, майже однакові, що обумовлено близькою специфікою живлення, екологічними особливостями у природних біоценозах. Проте висота мозкового відділу порівняно з загальною висотою черепа у борсука (61,02 \pm 4,73\%) в 1,51 разу менша $(P<0,001)$ за такий показник у куничі $(92 \pm 6,12 \%)$ завдяки добре розвиненому зовнішньому сагітальному гребеню. Його відносна

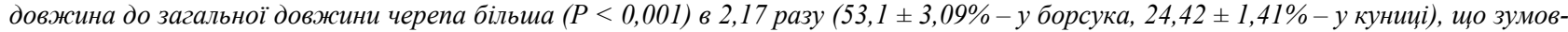
лено потужнішим розвитком жувальних м'язів, вискового зокрема.

Ключові слова: скелет голови, м'ясоїдні тварини, морфологія, краніометрія.

\section{Вступ}

Першочерговим у вивченні дикої фауни є дослідження з морфології, фізіології, екології тварин, які можуть дати базисний об'єм інформації щодо розробки нових наукових основ розведення і утримання тварин у неволі, а також підвищення їхньої чисельності в мисливських та промислових угіддях (HemandezRomero et al., 2015).

Хижі - середні та великі ссавці, що ведуть наземний спосіб життя, переважно м'ясоїдні тварини, про характер живлення яких свідчать певні пристосування, відображені у будові черепа (Asahara, 2013; ParesCasanova \& Cruz, 2014; Amaike et al., 2015).

Палеонтологічні джерела містять значну кількість інформації щодо еволюції хижих тварин, зокрема будови та розвитку скелету голови (Sabol, 2014; Jasinski \& Wallace, 2015; Potapova \& Lavrov, 2015; Spassov \& Geraads, 2015; Kitchener, 2016; Baryshnikov \& Alekseeva, 2017; Berte, 2017; Sansom et al., 2017; Law et al., 2018; Pop et al., 2018). Фахівці ж ветеринарної медицини при визначенні видових ознак близьких за будовою кісток черепа дрібних свійських, мисливських і промислових хижих тварин опиняються у важкій ситуації, оскільки джерела літератури щодо цього питання носять фрагментарний характер (Jurgelenas et al., 2007; Yatsenko, 2009; Rudyk \& Kot, 2011; Abramov et al., 2016; 2018).

Мета роботи - провести порівняльно-анатомічні дослідження будови черепа і визначити краніометричні показники в окремих представників ряду Хижі.

\section{Матеріал і методи досліджень}

Матеріалом досліджень слугували черепи собаки свійського - Canis lupus familiaris Linnaeus, 1758 (n = 6), кота свійського - Felis domesticus Linnaeus, $1758(\mathrm{n}=3)$, вовка - Canis lupus Linnaeus, $1758(\mathrm{n}=3)$, куниці кам'яної - Martes foina Erxleben, $1777(\mathrm{n}=6)$, тхора лісового - Mustela putorius Linnaeus, 1758 $(\mathrm{n}=2)$, борсука звичайного - Meles meles Linnaeus, 1758 ( $\mathrm{n}=6$ ), лисиці звичайної - Vulpes vulpes Linnaeus, $1758(\mathrm{n}=3)$. Всього досліджено 29 черепів. Використано порівняльно-анатомічний i краніометричний методи. Визначення промірів черепа проводили за 22 краніометричними точками штангенцирку- лем ДСТУ-10 з точністю до 0,05 мм (Lutsenko, 2015). Отримані результати обробляли варіаційностатистичним методом 3 використанням програмного пакету "Statistica 6" для Windows XP.

\section{Результати та їх обговорення}

Форма, будова, топографія кісток черепа тварин і вираженість кісткових утворів (гребені, відростки, ямки) залежать від розвитку м'язів голови, особливостей їх топографіï, форми та прикріплення до кісткової основи (Yatsenko, 2009; Asahara, 2013; ParesCasanova and Cruz, 2014).

Для черепа досліджуваних тварин ряду Хижі характерно добре виражений карковий і дещо слабше висковий гребені (рис. 1). Площа прикріплення вискового м'яза велика за рахунок розвитку по серединній лінії тім'яної кістки зовнішнього сагітального гребеня. Він прямує від каркового гребеня у ростральному напрямі та роздвоюється на вискові лінії напочатку (куниця, тхір) або на рівні середини (собака, вовк, лисиця, кіт) виличної дуги. У самців останнього виду тварин, на відміну від самок, зовнішній сагітальний гребінь прямує до лобової кістки нероздвоєним. Завдяки розвитку вискового м'яза, вилична дуга сильно виступає латерально, а вискова ямка має велику площу і зливається 3 очною ямкою. Остання у досліджуваних тварин, за винятком кота, не замкнена, оскільки виличний відросток лобової кістки короткий. Луска лобової кістки кота вигнута назовні і дугою опускається до лицевого відділу черепа. Вона містить одну пазуху. У собаки їх виявлено три.

Слізна кістка малого розміру і неправильної форми. Вискова кістка складається з луски, кам'янистої, барабанної (у кота і внутрішньобарабанної) частин. Барабанні міхури відносно великі, округлої або овальної форми. Гачок клиноподібної кістки короткий (у собаки) або довгий і загострений (у кота). Гілка нижньощелепної кістки містить жувальну і крилоподібну ямки для прикріплення однойменних м'язів. Ці ямки в ділянці кута нижньої щелепи збільшуються за рахунок кутового відростка, направленого каудально (рис. 2). Останній у вовка - короткий, широкий, дещо заокруглений, у тхора - виражений слабо, загнутий медіально. 

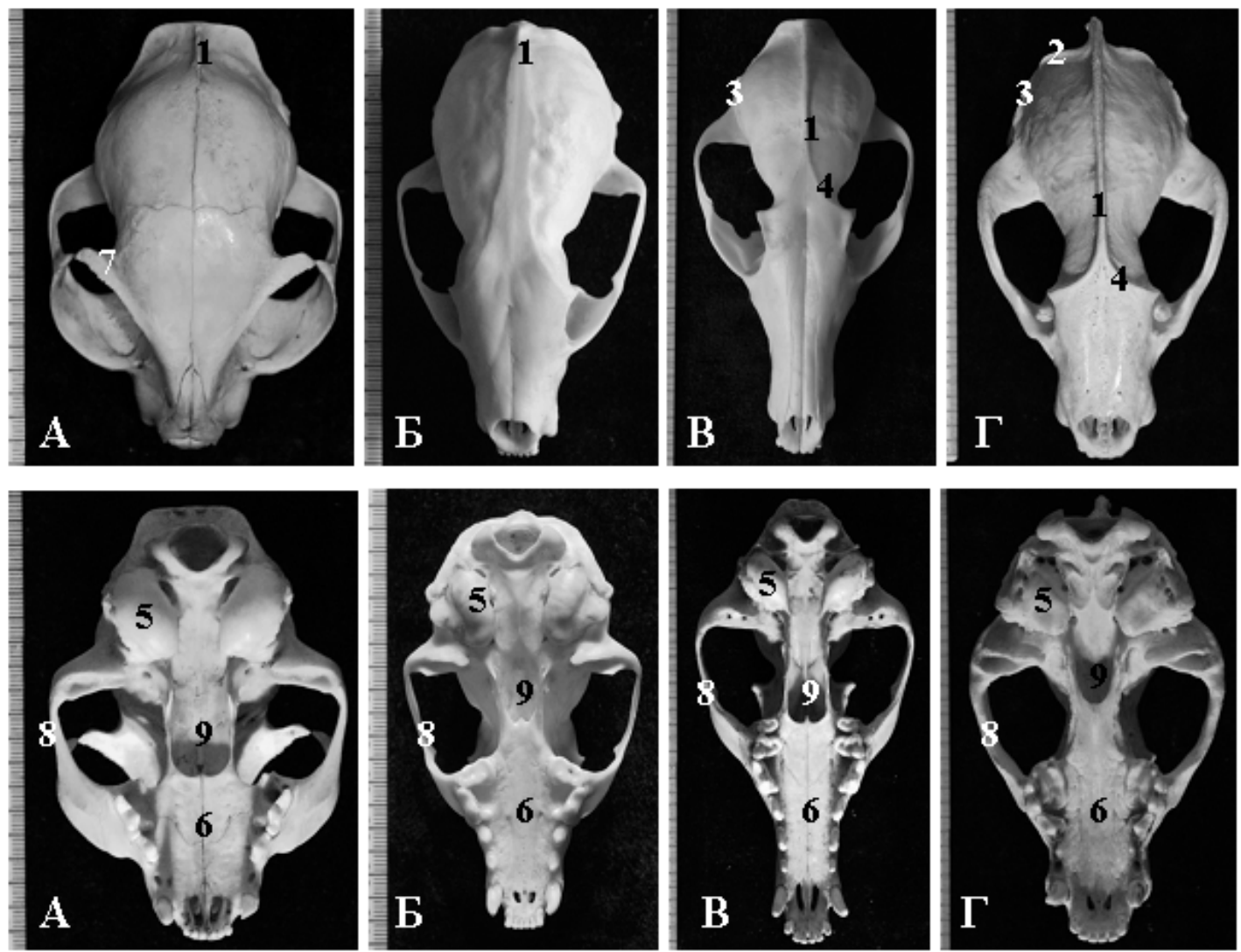

Рис. 1. Череп кота (А), куниці (Б), лисиці (В), борсука (Г) з дорсальної (верхній ряд) і вентральної (нижній ряд) поверхонь: 1 - зовнішній сагітальний гребінь; 2 - карковий гребінь; 3 - висковий гребінь, 4 - вискова лінія;

5 - барабанний міхур; 6 - кісткове піднебіння; 7 - виличний відросток лобової кістки; 8 - вилична дуга; 9 - хоани. Макропрепарати

Головна риса, яка об'єднує тварин ряду Хижі - зубна система (Pares-Casanova \& Cruz, 2014; HemandezRomero et al., 2015). Досліджувані тварини мають усі типи зубів, характерні для ссавців. Різці зовсім невеликі й слабкі. Ікла, навпаки, сильні та довгі. Кількість молярів і премолярів неоднакова: найбільша - у вовка, лисиці, собаки (26), дещо менша - у борсука, ку- ниці (22), найменша - у тхора (18), кота (14). Останній премоляр верхньої щелепи і перший моляр нижньої щелепи відрізняються за розміром та формою. У спеціальних анатомічних джерелах їх називають “хижі зуби” (Abramov et al., 2016; Kitchener, 2016; Abramov et al., 2018).
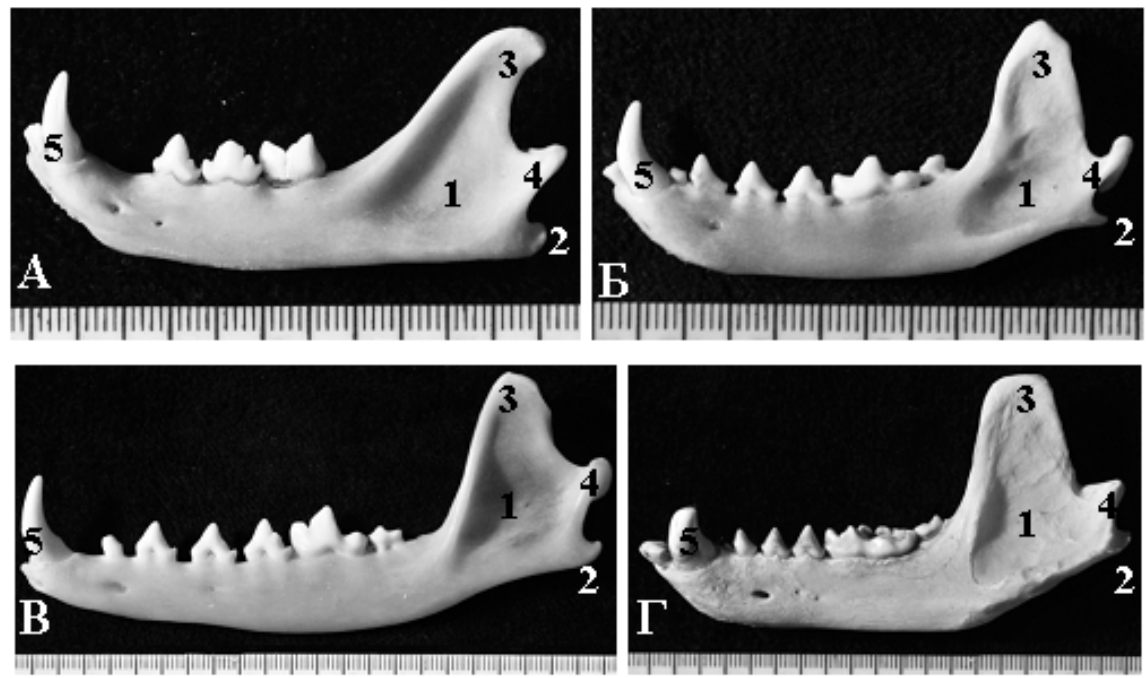

Рис. 2. Нижньощелепна кістка кішки (А), куниці (Б), лисиці (В), борсука (Г) з латеральної поверхні: 1 - ямка жувального м'яза; 2 - кутовий відросток; 3 - вінцевий відросток; 4 - виростковий відросток; 5 - ікло. Макропрепарати 
Абсолютні краніометричні показники борсука більші за такі показники куниці (табл. 1), оскільки прямо залежать від маси $(1,56 \pm 0,16$ кг - куниця, $13,43 \pm$ 2,16 кг - борсук) і розмірів $(49,12 \pm 3,73 \mathrm{~cm}-$ куниця, $78,63 \pm 4,12 \mathrm{~cm}-$ борсук) їхніх тіл. Найбільш різняться показники загальної довжини черепа (в 1,69 раза; $\mathrm{P}<0,001$ ), довжини кісткового піднебіння (в 1,82 разу; $\mathrm{P}<0,001)$, довжини зовнішнього сагітального гребеня (в 3,67 раза; Р < 0,001), ширини кісткового піднебіння на рівні першого премоляра і останнього моляра (в 2 разу; Р < 0,001), ширини хоан на рівні гачкоподібних відростків крилоподібної кістки (в 1,75 разу; $\mathrm{P}<0,01)$, ширини хоан на рівні каудального краю піднебінної кістки (в 2 рази; $\mathrm{P}<0,05)$, загальної висоти черепа (в 2,36 разу; $\mathrm{P}<0,001)$.

\section{Таблиця 1}

Краніометричні показники, мм $(\mathrm{M} \pm \mathrm{m}, \mathrm{n}=6)$

\begin{tabular}{|c|c|c|c|}
\hline & \multirow[b]{2}{*}{ Показники } & \multicolumn{2}{|c|}{ Вид тварин } \\
\hline & & $\begin{array}{c}\text { куниця } \\
\text { кам’яна }\end{array}$ & $\begin{array}{c}\text { борсук } \\
\text { звичайний }\end{array}$ \\
\hline \multicolumn{2}{|c|}{ Загальна довжина черепа } & $86 \pm 2,13$ & $145 \pm 4,03 * * *$ \\
\hline & кісткового піднебіння & $39 \pm 1,86$ & $71 \pm 2,95 * * *$ \\
\hline & верхньощелепного відділу твердого піднебіння & $27 \pm 1,45$ & $42 \pm 1,3 * * *$ \\
\hline & коміркового ряду верхньої щелепи & $32 \pm 1,72$ & $46 \pm 1,26^{* * *}$ \\
\hline & коміркового ряду нижньої щелепи & $35 \pm 0,93$ & $52 \pm 0,86^{* * *}$ \\
\hline & нижньої щелепи & $57 \pm 2,12$ & $94 \pm 3,04 * * *$ \\
\hline & зовнішнього сагітального гребеня & $21 \pm 1,3$ & $77 \pm 1,91 * * *$ \\
\hline \multicolumn{2}{|c|}{ Анатомічна лицьова вісь } & $54 \pm 1,15$ & $78 \pm 3,05 * * *$ \\
\hline \multicolumn{2}{|c|}{ Краніобазальна довжина } & $34 \pm 0,98$ & $52 \pm 2,13 * * *$ \\
\hline \multicolumn{2}{|r|}{ Найбільша ширина кісткового піднебіння } & $17 \pm 0,64$ & $21 \pm 0,87^{*}$ \\
\hline \multirow{12}{*}{$\begin{array}{l}\text { Зага } \\
\text { Вис } \\
\text { Саг } \\
\Phi р с\end{array}$} & черепа на рівні виличних дуг & $48 \pm 2,54$ & $80 \pm 3,69 * * *$ \\
\hline & черепа на рівні виличних відростків лобової кістки & $26 \pm 1,21$ & $35 \pm 0,93 * *$ \\
\hline & кісткового піднебіння на рівні першого премоляра & $10 \pm 0,69$ & $20 \pm 1,05 * * *$ \\
\hline & кісткового піднебіння на рівні останнього моляра & $10 \pm 0,77$ & $20 \pm 0,62 * * *$ \\
\hline & хоан на рівні гачкоподібних відростків крилоподібної кістки & $8 \pm 0,44$ & $14 \pm 0,56^{* *}$ \\
\hline & хоан на рівні каудального краю піднебінної кістки & $4 \pm 0,43$ & $8 \pm 0,48^{*}$ \\
\hline & потиличної кістки позаду виличних дуг & $30 \pm 1,45$ & $36 \pm 1,04 *$ \\
\hline & нижньої щелепи & $25 \pm 0,93$ & $42 \pm 2,08 * * *$ \\
\hline & льна висота черепа & $25 \pm 1,06$ & $59 \pm 2,04 * * *$ \\
\hline & ота мозкового черепа & $23 \pm 1,22$ & $36 \pm 1,95 * * *$ \\
\hline & гальний діаметр потиличного отвору & $9 \pm 0,48$ & $14 \pm 0,81 *$ \\
\hline & нтальний діаметр потиличного отвору & $11 \pm 0,44$ & $17 \pm 0,65 * *$ \\
\hline
\end{tabular}

Примітка: *-P $<0,05 ; * *-\mathrm{P}<0,01 ; * * *-\mathrm{P}<0,001$ порівняно з куницею

Щодо відносних краніометричних показників, переважна їх більшість у борсука, порівняно з такими у куниці, майже однакові, що можливо обумовлено близькою специфікою живлення та екологічними особливостями у природних біоценозах (Yatsenko, 2009; Rudyk \& Kot, 2011; Abramov et al., 2016; 2018). Довжина кісткового піднебіння становить майже половині загальної довжини черепа (45,35 $\pm 4,13 \%-$ у куниці, 48,97 $\pm 2,04 \%$ - у борсука). Показники відносної довжини верхньощелепного відділу твердого піднебіння і коміркового ряду верхньої щелепи до загальної довжини черепа між собою вірогідно (Р > 0,05) не відрізняються - 31,4 $\pm 3,22$ і $37,21 \pm 2,61 \%$ (куниця), 28,97 $\pm 3,16$ і 31,72 $\pm 2,21 \%$ (борсук). Відносна довжина коміркового ряду нижньої щелепи до загальної довжини черепа варіює у вузьких межах - від $35,86 \pm 3,12 \%$ (борсук) до 40,69 $\pm 2,09 \%$ (куниця). Відносна ширина черепа на рівні виличних дуг до загальної довжини черепа у борсука і куниці майже однакова $-55,17 \pm 4,16$ і 55,81 $\pm 3,04 \%$ відповідно. Відносний показник найбільшої ширини кісткового піднебіння до ширини черепа на рівні виличних дуг коливається від 26,25 $\pm 2,94 \%$ (борсук) до $35,42 \pm$ 3,04\% (куниця). Щодо відносних показників ширини кісткового піднебіння на рівні першого премоляра i останнього моляра до ширини черепа на рівні виличних дуг, вони однакові $(20,83 \pm 3,04$ і $20,83 \pm 2,45 \%$ у куниці, $25 \pm 1,94$ і $25 \pm 2,57 \%$ - у борсука). Дещо менші показники відносної ширини хоан на рівні гачкоподібних відростків крилоподібної кістки $(16,67 \pm 1,77 \%$ - у куниці, $17,5 \pm 1,04 \%-$ у борсука) та каудального краю піднебінної кістки $(8,33 \pm 1,36 \%$ - у куниці, $10 \pm 2,52 \%$ - у борсука). Завдяки добре розвиненому зовнішньому сагітальному гребеню, висота мозкового відділу відносно загальної висоти черепа у борсука $(61,02 \pm 4,73 \%)$ в 1,51 раза менша $(\mathrm{P}<0,001)$, ніж у куниці $(92 \pm 6,12 \%)$. Відносна довжина зовнішнього сагітального гребеня до загальної довжини черепа борсука, порівняно 3 куницею, більша $(\mathrm{P}<0,001)$ в 2,17 раза $(53,1 \pm 3,09$ проти $24,42 \pm$ $1,41 \%)$, що зумовлено потужнішим розвитком жувальних м'язів, вискового зокрема.

\section{Висновки}

1. Череп тварин ряду Хижі (кіт, вовк, собака, лисиця, куниця, тхір, борсук) має спільні анатомічні особливості будови (широка вискова ямка, глибока жуваль- 
на ямка, добре виражені карковий і зовнішній сагітальний гребені, наявність кутового відростка на нижній щелепі, відносно великі барабанні міхури, слабо розвинена слізна кістка) та видові відмінності (топографія роздвоєння зовнішнього сагітального гребеня, форма нижньощелепного кутового відростка, наявність внутрішньобарабанної частини вискової кістки).

2. Абсолютні краніометричні показники борсука більші за такі показники куниці, оскільки прямо залежать від маси та розмірів їхніх тіл. Більшість відносних показників черепа борсука, порівняно з такими куниці, майже однакові, що обумовлено близькою специфікою живлення та екологічними особливостями у природних біоценозах. Завдяки добре розвиненому зовнішньому сагітальному гребеню висота мозкового відділу відносно загальної висоти черепа у борсука в 1,51 разу менша $(\mathrm{P}<0,001)$, ніж у куниці. Відносна довжина зовнішнього сагітального гребеня до загальної довжини черепа борсука, порівняно $з$ куницею, більша (P < $0,001)$ в 2,17 разу, що зумовлено потужнішим розвитком жувальних м'язів, вискового зокрема.

Перспективи подальших досліджень. Проведення гістологічного дослідження 3 метою вивчення особливостей архітектоніки губчастої кісткової речовини в кістках черепа тварин ряду Хижі.

\section{References}

Abramov, A.V., Puzachenko, A.Y., \& Tumanov, I.L. (2016). Morphological Differentiation of the Skull in two Closely-related Mustelid Species (Carnivora Mustelidae). Zoological Studies, 55(1), 1-12. doi: 10.6620/ZS.2016.55-01.

Abramov, A., Puzachenko, A., \& Masuda, R. (2018). Cranial Variation in the Siberian Weasel Mustela sibirica (Carnivora, Mustelidae) and its Possible Taxonomic Implications. Zoological Studies, 57(14), 1-9. doi: 10.6620/ZS.2018.57-14.

Amaike, Y., Oishi, T., Uraguchi, K., Abramov, A., \& Masuda, R. (2015). Geographical variation in scull morphology in the Hokkaido population of the red fox, Vulpes vulpes. Mammal Study, 40(4), 245-256. doi: 10.3106/041.040.0405.

Asahara, M. (2013). Shape Variation in the Skull and Lower Carnassial in a Wild Population of Raccoon Dog (Nyctereutes procyonoides). Zoological Science of Japan, 30(3), 205-210. doi: 10.2108/zsj.30.205.

Baryshnikov, G.F., \& Alekseeva, E.V. (2017). Late Pleistocene and Holocene Mustela remains (Carnivora, Mustelidae) from Bliznets Cave in the Russian Far East. Russian Journal of Theriology, 16(1), 1-14. doi: 10.15298/rusjtheriol.16.1.01.

Berte, D.F. (2017). Remarks on the skull morphology of Canis lupaster Hemprich and Herenberg, 1832 from the collection of the Natural History Museum "G. Doria” of Genoa, Italy. Natural History Sciences, 4(1), 19-29. doi: 10.4081/nhs.2017.318.

Hemandez-Romero, P., Guerrero, J., \& Valdesopino, C. (2015). Morphological variability of the cranium of Lontra longicaudis (Carnivora: Mustelidae): a mor- phometric and geographic analysis. Zoological Studies, 54, 50. doi: 10.1186/s40555-015-0127-6.

Jasinski, S.E., \& Wallace, S.C. (2015). A Borophagine canid (Carnivora: Canidae: Borophaginae) from the middle Miocene Chesapeake Group of eastern North America. Journal of Paleontology, 89(6), 1082-1088. doi: $10.1017 /$ jpa.2016.17.

Jurgelenas, E., Daugnora, L., Monastyreckiene, E., \& Balciauskas, L. (2007). On the skull morphology of raccoon dog (Nyctereutes procyonoides) and red fox (Vulpes vulpes). Acta Zoologica Lituanica, 17(1), 4146. doi: 10.1080/13921657.2007.10512814.

Kitchener, A., Driscoll, C., \& Yamaguchi, N. (2016). What is a Snow Leopard? Taxonomy, morphology and phylogeny: Snow Leopards, 3-11. doi: 10.1016/B978-0-12-802213-9.00001-8.

Law, C., Duran, E., Hung, N., Richards, E., Santillan, I., \& Menta, R. (2018). Effects of diet on cranial morphology and biting ability in musteloid mammals. Journal of Evolutionary Biology, 31(12), 1918-1931. doi: $10.1111 /$ jeb.13385.

Lutsenko, P.O. (2015). Biomorfolohiia cherepa deiakykh predstavnykiv rodu vovkiv. Problemy zooinzhenerii ta veterynarnoi medytsyny, 30(2), 409-420 (in Ukrainian).

Pares-Casanova, M., \& Cruz, S. (2014). Larger wild felids exhibit longer dental skeletons. Journal of Zoological and Bioscience Research. 1(4), 22-26. http://www.journalzbr.com/issues.html.

Pop, X., Gudea, A., \& Damian, A. (2018). Applied Craniometry for Dog Skulls from Pecica-«Santul Mare» (Arad County) and Santion (Bihor County) Bronze Age Sites. Bulletin UASVM Veterinary Medicine, 75(2), 12-18. doi: 10.15835/buasvmen-vm:2018.0005.

Potapova, E.G., \& Lavrov, A.U. (2015). Morphology of the auditory region of the skull in Dinofelis sp. (Felidae, Canivora). Paleontological Journal, 49(2), 190199. doi: 10.1134/S0031030115020082.

Rudyk, S.K., \& Kot, T.F. (2011). Anatomiia kishky. Chastyna 1. Aparat rukhu. Polissia, Zhytomyr (in Ukrainian).

Sabol, M. (2014). Panthera fossilis (Reichenau, 1906) (Felidae, Carnivora) from Za Hájovnou Cave (Moravia, the Czech Republic): a fossil record from 19872007. Sborník Národního musea v Praze, 70(1-2), 5970. doi: 10.14446/AMNP.2014.59.

Sansom, R., Wills, M., \& Williams, T. (2017). Dental Data Perform Relatively Poorly in Reconstructing Mammal Phylogenies: Morphological Partitions Evaluated with Molecular Benchmarks. Syst. Biol, 66(5), 813-822. doi: 10.1093/sysbio/syw116.

Spassov, N., \& Geraads, D. (2015). A New Felid from the Late Miocene of the Balkans and the Contents of the Genus Metailurus Zdansky, 1924 (Carnivora, Felidae). Journal of Mammalian Evolution, 22(1), 45-56. doi: 10.1007/s10914-014-9266-5.

Yatsenko, I.V. (2009). Strukturni parametry skeleta ssavtsiv yak obiekty sudovo-veterynarnoi ekspertyzy pry vyznachenni vydovoi nalezhnosti biolohichnoho materialu. PhD [thesis]. Kyiv (in Ukrainian). 